\title{
Formação pós-graduada de professores: construindo uma pedagogia da experiência, rumo a uma educação mais democrática ${ }^{1}$
}

\section{Postgraduate teacher education: building a pedagogy of experience, towards a more democratic education}

\author{
Flávia Vieira ${ }^{2}$
}

\begin{abstract}
RESUMO
A formação pós-graduada pode favorecer a reconfiguração do pensamento e das práticas dos professores, rumo a uma educação mais democrática nas escolas. Com base neste pressuposto, defende-se uma pedagogia da experiência nos contextos formativos e descreve-se uma estratégia desenvolvida numa disciplina de um mestrado destinado a professores. Nesse contexto, os formandos desenvolvem experiências de investigação-ação focadas na autonomia dos seus alunos e produzem narrativas onde descrevem e teorizam essas experiências, refletindo sobre o seu valor pedagógico e formativo. A partir da análise de seis dessas narrativas, é discutido o potencial emancipatório da abordagem na construção de uma visão crítica da educação e de práticas pedagógicas de orientação democrática.
\end{abstract}

Palavras-chave: formação de professores; experiência educativa; emancipação profissional.

\begin{abstract}
Postgraduate teacher education can reframe teachers' thinking and actions towards a more democratic education in schools. On the basis of this
\end{abstract}

DOI: $10.1590 / 0104-4060.49139$

1 Este trabalho é financiado pelo Centro de Investigação em Educação (CIEd), projetos UID/ CED/1661/2013 e UID/CED/1661/2016, Instituto de Educação, Universidade do Minho, através de fundos nacionais da FCT/MCTES-PT.

2 Centro de Investigação em Educação do Instituto de Educação da Universidade do Minho. Braga, Portugal. Campus de Gualtar, 4710-057.E-mail: flaviav@ie.uminho.pt 
assumption, a pedagogy of experience in teacher education settings is advocated and a strategy developed in a course of master degree for inservice teachers is described. In that context, teachers develop action-research experiences focused on the learners' autonomy and they produce narratives in which they describe and theorize those experiences, reflecting on their pedagogical and formative value. Through the analysis of six narratives, I will discuss the empowering potential of the approach in the construction of a critical view of education and democratic pedagogical practices.

Keywords: teacher education; educational experience; professional empowerment.

\section{Há que abrir a janela...}

Tomando aqui as ideias de Larrosa Bondía (2010, p. 88), falar de experiência em educação significa dizer não ao que torna a educação insatisfatória e fazer perguntas que nos orientem para outros modos de educar, abrindo a janela ao desconhecido. Assim, abrir a janela pode constituir uma metáfora para a busca de novos horizontes para a educação, exigindo uma interrogação das culturas pedagógicas no que elas são, devem e podem ser. Isto significa que o ensino e a formação constituem campos de questionamento ideológico acerca da natureza e dos propósitos da experiência educativa, com a finalidade de a (re)conhecer e transformar.

Num manifesto radical contra políticas educativas neoliberais e mercantilistas, Giroux (2013) sublinha os perigos de uma "pedagogia da repressão" que "mata o espírito" e "promove o conformismo", e onde não se aprende o respeito pela democracia ou a relação entre a aprendizagem escolar e a mudança social. (GIROUX, 2013, parágrafo 15) ${ }^{3}$. A emancipação dos professores face a uma pedagogia desta natureza, que marca ainda muitos contextos de trabalho, implica uma visão crítica da educação e a exploração de intervenções dialógicas e inclusivas, comprometidas com valores como a liberdade, a justiça e a responsabilidade social. A construção do saber e da identidade profissional é assim concebida como um processo de indagação e libertação, assente na esperança de uma outra educação, e as pedagogias de formação deverão centrar-se na experiência educativa e integrar processos de investigação dessa experiência, em oposição a uma conceção positivista da formação, assente na hegemonia do conhecimento académico e na desvalorização do saber construído a partir da experiência.

3 Indica-se o parágrafo do texto, uma vez que este não é paginado. 
Com base nesses pressupostos, apresento uma estratégia de formação enquadrada numa pedagogia da experiência, na qual os formandos desenvolvem e narrativizam experiências pedagógicas de investigação-ação, e analiso o seu potencial emancipatório com base em seis narrativas produzidas nesse contexto. A estratégia proposta tem sido por mim desenvolvida na disciplina de Educação em Línguas e Supervisão Pedagógica do Mestrado em Ciências da Educação - Supervisão Pedagógica na Educação em Línguas da Universidade do Minho, dirigido a professores profissionalizados de língua materna e estrangeira $^{4}$ (v. VIEIRA, 2011a/b, 2012, 2014a/b). Embora a estratégia se reporte a um contexto curricular específico, creio que será transferível, com as devidas adaptações, para outros cenários de formação contínua e especializada nos quais se explorarem caminhos de emancipação profissional.

\section{Para uma pedagogia da experiência na formação de professores}

O princípio estruturante de uma pedagogia da experiência na formação de professores consiste em tomar a experiência educativa como objeto de (re) conhecimento e transformação, criando-se condições para a democratização da tomada de decisões sobre o que conhecer e como conhecer, e transformando os interesses e as necessidades dos professores em planos de ação promotores da sua "liberdade intelectual" como liberdade de observação e avaliação exercida ao serviço de finalidades com valor educativo. (DEWEY, 1963, p. 61). Em termos curriculares, uma pedagogia da experiência desloca o núcleo da formação para o terreno da ação profissional, promovendo processos de teorização da experiência e autenticação de teorias com uma finalidade transformadora, facilitando a construção de teorias práticas razoáveis, localmente validadas e socialmente úteis, que permitam aos professores compreender a complexidade das situações educativas, embrenhar-se nelas e tomar decisões conceptual e moralmente ajustadas aos interesses de todos quantos nelas participam. (VIEIRA, 2009, p. 39).

A estratégia aqui proposta, desenvolvida numa disciplina de um mestrado destinado a professores de línguas, promove uma aproximação à experiência educativa através da análise e construção de casos. O uso de casos, associado

4 Este Mestrado tem a duração de dois anos (120 unidades de crédito), com um ano curricular e um ano para a dissertação. A disciplina em causa decorre no primeiro semestre do curso (45h presenciais). Embora se trate de um mestrado de natureza académica, tem também uma forte dimensão profissionalizante e muitas das dissertações resultam de projetos desenvolvidos nas escolas dos formandos. 
ao uso de narrativas de ensino, tem sido recomendado na formação de professores como meio de reforçar a relação teoria-prática e promover a mudança de conceções e práticas profissionais. (v. SHULMAN, J., 1992; SHULMAN, L., 2004; JIMÉNEZ RAYA; VIEIRA, 2015)5. O reconhecimento da existência de um caso decorre da interpretação de uma experiência (de outrem ou pessoal) que ilustra uma ou mais situações, ideias, princípios, dilemas..., e que encontra nessa propriedade ilustrativa o seu estatuto enquanto caso de um fenómeno mais vasto. Assim, o uso de casos implica movimentos de teorização da prática.

No âmbito da disciplina de mestrado, a análise de casos consiste na leitura crítica de narrativas de experiências de outros professores, em articulação com os conteúdos programáticos. Centrar-me-ei aqui na vertente da construção de casos, que envolve os professores-formandos no desenvolvimento e narrativização de experiências de investigação-ação onde exploram uma pedagogia para a autonomia na educação em línguas. (JIMÉNEZ RAYA; LAMB; VIEIRA, 2007). Os professores começam por desenhar as experiências em grupos, com o apoio de um guião cujo preenchimento vai sendo acompanhado e discutido. Esse guião integra questões de ordem conceptual, ética e metodológica, relativas à identificação de um problema a explorar, ao contexto de experimentação e às estratégias de intervenção e recolha de dados, à visão de educação que subjaz ao plano de ação e ao impacto esperado nos alunos e no professor. Cada grupo de professores desenha uma intervenção de curta duração e elabora instrumentos didáticos e de recolha de informação com o meu apoio. Posteriormente, implementa a sua experiência numa das turmas de um dos professores do grupo, analisa a informação recolhida e produz uma narrativa com uma extensão média de 15 páginas, na qual integra contributos teóricos relevantes à fundamentação e à interpretação da experiência. $\mathrm{O}$ trabalho desenvolvido visa fomentar processos de supervisão colaborativa das práticas pedagógicas e elevar o sentido de agência dos professores, entendidos como intelectuais críticos e não como executores de programas pré-definidos. (SMYTH, 1997; KINCHELOE, 2003, 2006; GIROUX, 2013). Embora as experiências sejam articuladas com o programa nacional das disciplinas, buscam a promoção da autonomia dos alunos e implicam uma reconfiguração dos papéis pedagógicos, assim como uma postura indagatória do professor face à prática.

A produção de narrativas da experiência adquire um papel central na estratégia, apresentando um elevado potencial no desenvolvimento da racionalidade profissional, uma racionalidade reflexiva, multidimensional e impregnada de dilemas, que supõe uma relação dialética entre o que se pensa e o que se faz. (v. CLANDININ, 2007; JOHNSON; GOLOMBEK, 2002; MOREIRA, 2011a/b;

5 Ver também o artigo de Manuel Jiménez Raya no presente número temático. 
WEBSTER; MERTOVA, 2007). As narrativas produzidas assumem uma função descritiva mas sobretudo problematizadora e projetiva, implicando a construção situada de interpretações plausíveis através de "linguagens da experiência" (LARROSA BONDÍA, 2010), sendo a escrita entendida como um método de (auto)conhecimento que simultaneamente nos afasta e aproxima da experiência vivida. (VAN MANEN, 1990). Estas narrativas constituem a principal fonte de acesso aos processos de reconstrução do pensamento e da ação dos professores, permitindo-nos compreender o potencial emancipatório da estratégia. No ponto seguinte, identifico sinais de emancipação profissional com base numa análise seletiva de seis narrativas produzidas neste contexto.

\section{Narrativas da experiência: sinais de emancipação profissional}

A fim de evidenciar sinais de emancipação profissional, analisei de forma seletiva seis narrativas de seis grupos de professoras-formandas, focando-me em duas dimensões inter-relacionadas dessa emancipação: construção de uma visão crítica da educação e desenvolvimento de intervenções pedagógicas de orientação democrática.

As seis narrativas analisadas, produzidas no âmbito da disciplina, foram posteriormente publicadas como capítulos de uma coletânea por mim organizada (VIEIRA, 2014a) e é sobre as versões publicadas que incide a análise ${ }^{6}$. Numa abordagem qualitativa e exploratória, começo por identificar os pontos de partida e os caminhos de transformação traçados nas experiências relatadas, para em seguida ilustrar de que forma integram a construção de uma visão crítica da educação e a exploração de práticas de orientação democrática. Utilizo excertos significativos das narrativas e realizo movimentos de metainterpretação, na linha da investigação narrativa como forma de acesso à racionalidade dos professores e aos processos de desenvolvimento profissional. (JOHNSON; GOLOMBEK, 2002; WEBSTER; MERTOVA, 2007).

As narrativas relatam casos de promoção da autonomia dos alunos, reportando-se a experiências de investigação-ação realizadas em turmas de escolas públicas, cinco no $9^{\circ}$ ano do Ensino Básico e uma no $10^{\circ}$ ano do En-

6 As narrativas publicadas correspondem às versões revistas pelos grupos no âmbito da disciplina, em função do meu feedback na sua avaliação final. As narrativas são enviadas aos grupos, solicitando-se, como tarefa opcional, que as revejam e me autorizem a utilizá-las noutros contextos. A sua publicação foi feita com o consentimento e a colaboração das professoras, que figuram como autoras dos respetivos capítulos da coletânea. 
sino Secundário, integrando 21 professoras de Inglês. Todas as experiências exigiram um posicionamento crítico face a práticas estabelecidas e o desenho de práticas alternativas. No Quadro 1 apresento os títulos e as autoras das narrativas, sintetizando os problemas identificados e os caminhos didáticos de transformação traçados.

\section{QUADRO 1 - EXPERIÊNCIAS: PONTOS DE PARTIDA E CAMINHOS DE TRANSFOR- MAÇÃO}

\begin{tabular}{|c|c|c|}
\hline $\begin{array}{l}\text { Experiências (título e } \\
\text { autoria das narrativas) }\end{array}$ & Pontos de partida: problemas & $\begin{array}{l}\text { Caminhos didáticos de } \\
\text { transformação }\end{array}$ \\
\hline $\begin{array}{l}\text { TPC } C^{*} \text { da Tortura Para } \\
\text { Crianças ao Tempo } \\
\text { Para Criar } \\
\text { (BRANDÃO; MONTEIRO; } \\
\text { COSTA, 2014) }\end{array}$ & $\begin{array}{l}\text { Práticas de trabalho de casa como } \\
\text { reprodução da aula, resistências e } \\
\text { baixo envolvimento dos alunos, } \\
\text { dúvidas sobre a utilidade desta } \\
\text { prática escolar rotinizada }\end{array}$ & $\begin{array}{l}\text { Fomentar a iniciativa e a } \\
\text { criatividade nos trabalhos } \\
\text { de casa, a compreensão e a } \\
\text { expansão das suas funções, } \\
\text { a auto/corregulação das } \\
\text { aprendizagens, a avaliação } \\
\text { participada do ensino }\end{array}$ \\
\hline $\begin{array}{l}\text { Quebra de rotinas - Ler com } \\
\text { olhos de ver? Ver com olhos } \\
\text { de ler! } \\
\text { (FERREIRA, P. et al., 2014) }\end{array}$ & $\begin{array}{l}\text { Práticas de leitura mecanicistas, } \\
\text { alheamento dos alunos, } \\
\text { desconhecimento face a } \\
\text { estratégias e dificuldades de } \\
\text { compreensão textual }\end{array}$ & $\begin{array}{l}\text { Fomentar a relação leitor-texto, } \\
\text { a compreensão de dificuldades } \\
\text { e estratégias de leitura, a auto/ } \\
\text { corregulação de aprendizagens, a } \\
\text { avaliação participada do ensino }\end{array}$ \\
\hline $\begin{array}{l}\text { Aprender para falar... Falar } \\
\text { para aprender... } \\
(\text { COSTA; BARREIRO, } \\
2014)\end{array}$ & $\begin{array}{l}\text { Práticas de interação oral } \\
\text { centradas no professor, baixo } \\
\text { envolvimento dos alunos, ausência } \\
\text { de estratégias de regulação do } \\
\text { discurso e da aprendizagem }\end{array}$ & $\begin{array}{l}\text { Fomentar a interação entre os } \\
\text { alunos, o uso de estratégias } \\
\text { de comunicação, a auto/ } \\
\text { corregulação de aprendizagens, a } \\
\text { avaliação participada do ensino }\end{array}$ \\
\hline $\begin{array}{l}\text { Apresentações orais - Um } \\
\text { caso de (in/ter)dependências } \\
\text { (FERREIRA, S. et al., 2014) }\end{array}$ & $\begin{array}{l}\text { Práticas de apresentação oral } \\
\text { de trabalhos pouco apoiadas e } \\
\text { malsucedidas, falta de estratégias } \\
\text { preparatórias, baixa compreensão } \\
\text { de critérios de avaliação }\end{array}$ & $\begin{array}{l}\text { Fomentar estratégias de } \\
\text { preparação de apresentações } \\
\text { orais, a auto/corregulação de } \\
\text { aprendizagens, a avaliação } \\
\text { participada do ensino }\end{array}$ \\
\hline $\begin{array}{l}\text { Leitura oral... qual éo } \\
\text { drama afinal? } \\
\text { (TEIXEIRA et al., 2014) }\end{array}$ & $\begin{array}{l}\text { Práticas de leitura oral } \\
\text { mecanicistas, resistência e } \\
\text { insucesso dos alunos, falta } \\
\text { de estratégias preparatórias e } \\
\text { motivadoras }\end{array}$ & $\begin{array}{l}\text { Fomentar estratégias de } \\
\text { preparação da leitura oral } \\
\text { expressiva, a auto/corregulação } \\
\text { de aprendizagens, a avaliação } \\
\text { participada do ensino }\end{array}$ \\
\hline $\begin{array}{l}\text { Todos a bordo - Uma } \\
\text { experiência em trabalho } \\
\text { colaborativo }\end{array}$ & $\begin{array}{l}\text { Resistência dos professores à } \\
\text { prática do trabalho de grupo, } \\
\text { motivada por experiências } \\
\text { insatisfatórias e desconhecimento } \\
\text { de potencialidades da } \\
\text { aprendizagem cooperativa }\end{array}$ & $\begin{array}{l}\text { Fomentar a aprendizagem } \\
\text { cooperativa, a auto/corregulação } \\
\text { de aprendizagens, a avaliação } \\
\text { participada do ensino }\end{array}$ \\
\hline
\end{tabular}

FONTE: A autora (2016).

* A sigla TPC é usada em Portugal para referir o Trabalho Para Casa, ou seja, as tarefas que os professores solicitam aos alunos entre as aulas e que, no nosso contexto, são uma prática muito frequente. $\mathrm{Na}$ sua narrativa, as professoras explicam que os alunos traduzem muitas vezes essa sigla como Tortura Para Crianças, o que é tomado no título da narrativa. 
A identificação de problemas e o desenho de caminhos alternativos implicam a construção de uma visão crítica da educação, essencial à emancipação profissional. Como sublinha Smyth (1997, p. 1102), os professores deverão interrogar-se quanto à origem, natureza e direção das práticas escolares, questionando as finalidades e interesses que servem, a visão de educação que lhes subjaz, os dilemas e contradições que apresentam e as alternativas que melhor poderão servir propósitos humanistas e democráticos. As vozes das professoras dão conta deste tipo de (auto-)questionamento, como acontece no excerto a seguir apresentado, onde P. Ferreira et al. (2014) justificam a exploração de práticas alternativas de leitura, "sacudindo rotinas", "rompendo tradições", "despertando os alunos do seu entorpecimento" e "quebrando (des)encantos":

\section{Era uma vez...}

Todas as histórias começam assim. Mas afinal cada história nunca representa uma só vez e cada vez que alguém a lê, é uma nova vez. Cada vez é uma nova voz que se escuta e também uma voz nova que nasce da voz que se escuta.

Por que serão as nossas salas de aula tão silenciosas quando se realizam tarefas de leitura?

Sendo a leitura uma viagem tão maravilhosa, por que razão os nossos alunos a assumem com tanto sacrifício? Porque recusam o desafio de interagir com os textos e se especializam num trabalho maçador de recorte e cópia de palavras sem sentido? ${ }^{7}$

Partimos à procura de respostas, desafiando os alunos para a realização de tarefas capazes de os despertar do entorpecimento que deles se apodera quando lhes propomos ler na aula de Inglês. Sacudimos as rotinas. Quisemos conhecer as causas destes (des)encontros infelizes com a leitura. Quisemos romper o silêncio dos textos, tornando audível a voz dos alunos. Assim nasceu a história desta experiência: um estudo de caso das dificuldades de leitura dos nossos alunos. A criação de questionários em língua materna (LM) para tarefas de leitura em língua estrangeira (LE) surgiu como estratégia de intervenção, marcando uma quebra de rotinas nas práticas habituais de professoras e alunos. Pretendíamos que fosse um contributo para a desconstrução das suas teorias pessoais relativamente ao uso da LM, que tradicionalmente é encarado como um entrave à aprendizagem da LE. A utilização da LM nas tarefas desenvolvidas nas aulas de LE adquire, nesta experiência, um papel fulcral no (re)conhecimento das

7 Referência a estratégias mecanicistas de resposta a perguntas em tarefas escritas de interpretação textual, em que os alunos identificam, a partir de pistas textuais identificadas nas perguntas fornecidas, segmentos textuais que reproduzem nas suas respostas, sem que isso signifique, necessariamente, que compreenderam as perguntas e/ou o texto. 
dificuldades dos alunos ao nível da leitura. Procurámos romper, assim, com uma pesada tradição que tem ignorado as potencialidades do uso da LM em determinadas situações de ensino e aprendizagem de uma LE. Ler com olhos de ver? - a leitura tem de ser muito mais do que um simples relance sobre o texto; Ver com olhos de ler! - sim, ver para além da superficialidade das palavras impressas; ver com os nossos olhos carregados de imagens, ver com os nossos olhos capazes de acrescentar pontos aos contos.

Quebrámos o (des)encanto? Libertámos os alunos da "tortura dos significados estabelecidos" (KINCHELOE, 2006: 50)? Talvez não tenhamos conseguido desamarrar todas as correias, mas, pelo menos, conseguimos romper o silêncio e abrir caminhos... (P. FERREIRA et al., 2014, p. 68-69).

Nas palavras destas professoras (P. FERREIRA et al., 2014, p. 88), “A cultura da escola é muitas vezes construída no sentido de calar a voz dos alunos. Parecem moldados para agir de acordo com essa condição, e o seu 'eu' é condicionado a não ver para além do que normalmente fazem". Esta visão, comum a todas as experiências, justifica o desenho de estratégias que ampliam a participação dos alunos na construção da pedagogia. Tomando o exemplo da experiência de S. Ferreira et al. (2014), centrada na apresentação oral de trabalhos, a Figura 1 transcreve parte de uma tabela elaborada pelas professoras para evidenciar mudanças nas tarefas e papéis pedagógicos, permitindo-nos observar que a nova abordagem é mais democrática: mais transparente, negociada, cooperativa e participada.

Nesta como nas restantes experiências, o desenvolvimento de competências académicas (linguístico-comunicativas) é associado ao desenvolvimento de competências de aprendizagem, uma ideia bem expressa por Costa e Barreiro (2014), cuja experiência explorou a interação oral:

Aprender para falar é necessário, porém não é suficiente. É preciso aprender para falar tendo em conta o interesse de comunicar algo a alguém e com alguma intenção. Mas isso ainda não basta! É também preciso falar para aprender, porque é preciso falar do que se aprende e sobre como se aprende, falar para aprender a negociar e a decidir. (COSTA; BARREIRO, 2014, p. 90).

Ampliar a voz dos alunos no sentido de promover a sua autonomia implica questioná-los sobre representações e vivências de aprendizagem. Para esse efeito, são construídos instrumentos de recolha de informação com propósitos pedagógico-investigativos, que favorecem a construção de uma pedagogia dialógica, como se observa no seguinte testemunho: 
FIGURA 1 - RECONSTRUÇÃO DA PRÁTICA DE APRESENTAÇÃO ORAL DE TRABALHOS

\begin{tabular}{|c|c|}
\hline Prática pedagógica anterior & Experiência pedagógica \\
\hline Indicação de um tema único & Possibilidade de escolha entre três subtemas \\
\hline \multicolumn{2}{|c|}{$\begin{array}{l}\text { Apresentação de uma proposta de estrutura de organização do trabalho e seleção de estruturas } \\
\text { linguísticas úteis (com a colaboração dos alunos) }\end{array}$} \\
\hline & $\begin{array}{l}\text { Indicação/sugestão de fontes de consulta: endereços sítios na } \\
\text { internet úteis para realização do trabalho }\end{array}$ \\
\hline $\begin{array}{l}\text { Conhecimento das categorias de } \\
\text { avaliação da oralidade }\end{array}$ & $\begin{array}{l}\text { Apresentação de categorias de avaliação e descritores } \\
\text { simplificados que esclarecem o que é avaliado em cada } \\
\text { categoria }\end{array}$ \\
\hline \begin{tabular}{|l|}
$\begin{array}{l}\text { Preparação individual da } \\
\text { apresentação oral }\end{array}$ \\
\end{tabular} & Preparação colaborativa da apresentação oral (em pares) \\
\hline $\begin{array}{l}\text { Pesquisa e redação do texto da } \\
\text { apresentação oral fora da sala de aula }\end{array}$ & $\begin{array}{l}\text { Pesquisa fora da sala de aula e redação do texto da } \\
\text { apresentação oral na sala de aula (com recurso a dicionário } \\
\text { bilingue) }\end{array}$ \\
\hline \multicolumn{2}{|c|}{ Feedback da professora sobre o texto (enviado por correio eletrónico) } \\
\hline \multicolumn{2}{|c|}{ Memorização do texto da apresentação oral fora da sala de aula } \\
\hline & $\begin{array}{l}\text { Treino da apresentação em aula, sem que os alunos estejam } \\
\text { sujeitos a avaliação (em pares) }\end{array}$ \\
\hline Apresentação oral final individual & $\begin{array}{l}\text { Apresentação oral final em pares } \\
\text { Gravação de áudio das apresentações orais }\end{array}$ \\
\hline \multirow{3}{*}{$\begin{array}{l}\text { Avaliação da professora } \\
\text { imediatamente após a realização de } \\
\text { todas as apresentações orais }\end{array}$} & $\begin{array}{l}\text { Autoavaliação dos alunos após a realização das } \\
\text { apresentações orais }\end{array}$ \\
\hline & $\begin{array}{l}\text { Audição das suas prestações seguida de uma segunda } \\
\text { autoavaliação }\end{array}$ \\
\hline & $\begin{array}{l}\text { Comparação e análise dos resultados da avaliação da } \\
\text { professora e das autoavaliações dos alunos }\end{array}$ \\
\hline
\end{tabular}

FONTE: Adaptado de S. Ferreira et al. (2014, p. 116-117).

A professora questionou os alunos acerca de algumas das respostas [ao questionário inicial], de forma a compreendê-las melhor e poder ir ao encontro das suas necessidades e interesses, mas também como estratégia de consciencialização das potencialidades do TPC e sensibilização para a experiência a realizar. A este propósito, Kincheloe (2003, p. 136) refere que "o professor investigador estuda os alunos como se fossem textos a serem decifrados". Segundo este autor (2006), ninguém pode ter um conhecimento mais profundo dos alunos do que os professores. São eles que os ouvem dia após dia, monitorizam o seu trabalho, escutam os seus problemas, aplaudem os seus sucessos. Quando os professores ouvem os seus alunos e os questionam relativamente às suas opiniões e perspetivas, não só se cria uma relação mais saudável, autêntica e dialógica, como se promove a autoestima dos alunos, em virtude da atenção e interesse demonstrados pelo professor. (BRANDÃO; MONTEIRO; COSTA, 2014, p. 60). 
O envolvimento dos alunos na auto/corregulação das aprendizagens constitui um elemento central da orientação democrática das experiências realizadas, fomentando o conhecimento metacognitivo, a capacidade de aprender e a negociação pedagógica. Apresenta-se um exemplo na Figura 2, relativo à monitorização regular de competências sociais na aprendizagem cooperativa, explorada na experiência de Vasconcelos, Costa e Gonçalves (2014).

FIGURA 2 - INSTRUMENTO DE REGULAÇÃO DA APRENDIZAGEM COOPERATIVA

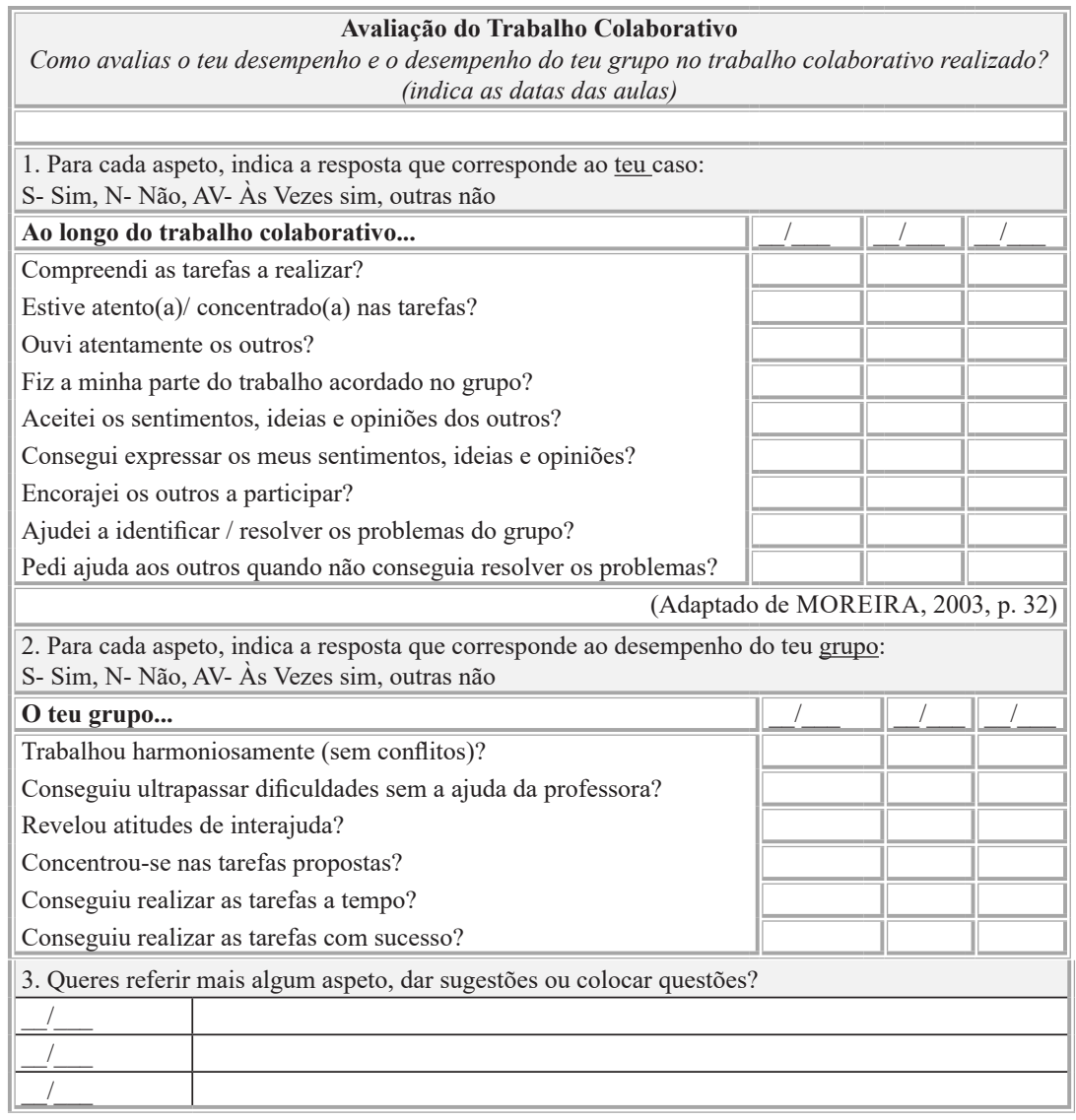

FONTE: Vasconcelos, Costa e Gonçalves (2014, p. 153).

Este tipo de instrumentos permite integrara voz dos alunos na análise das práticas. A Figura 3, relativa à experiência de Teixeira et al. (2014) sobre a leitura 
oral, ilustra ainda a possibilidade de integrar a voz dos alunos na construção dos instrumentos utilizados. Neste instrumento, os alunos avaliam e comparam os problemas que sentiram numa leitura oral inicial sem preparação prévia e na leitura final previamente preparada por eles. $\mathrm{O}$ instrumento combina a linguagem dos alunos, relativa a problemas de leitura verbalizados em diálogo com a professora e registados no quadro a quando da tarefa inicial (não fui expressivo, li demasiado baixo, etc.), com a linguagem da professora sobre critérios de qualidade da leitura oral a que esses problemas se reportam (entoação e expressividade, ritmo e pontuação, etc.). $\mathrm{O}$ instrumento ilustra, deste modo, o que Shor (1992) designa como um "terceiro idioma", resultante do cruzamento de linguagens e facilitador da intercompreensão em contexto pedagógico.

\section{FIGURA 3 - INSTRUMENTO DE AUTOAVALIAÇÃO FINAL DA LEITURA ORAL EX- PRESSIVA}

\section{Como desenvolvo a leitura oral expressiva na aula de língua inglesa?}

Proponho que reflitas sobre a experiencia que realizaste nas últimas duas aulas e compares o teu desempenho nas duas fases de leitura oral expressiva. Assinala as respostas, utilizando a seguinte escala: $\sqrt{ }$-Senti bastante o problema /? - Senti pouco o problema / X-Não senti o problema

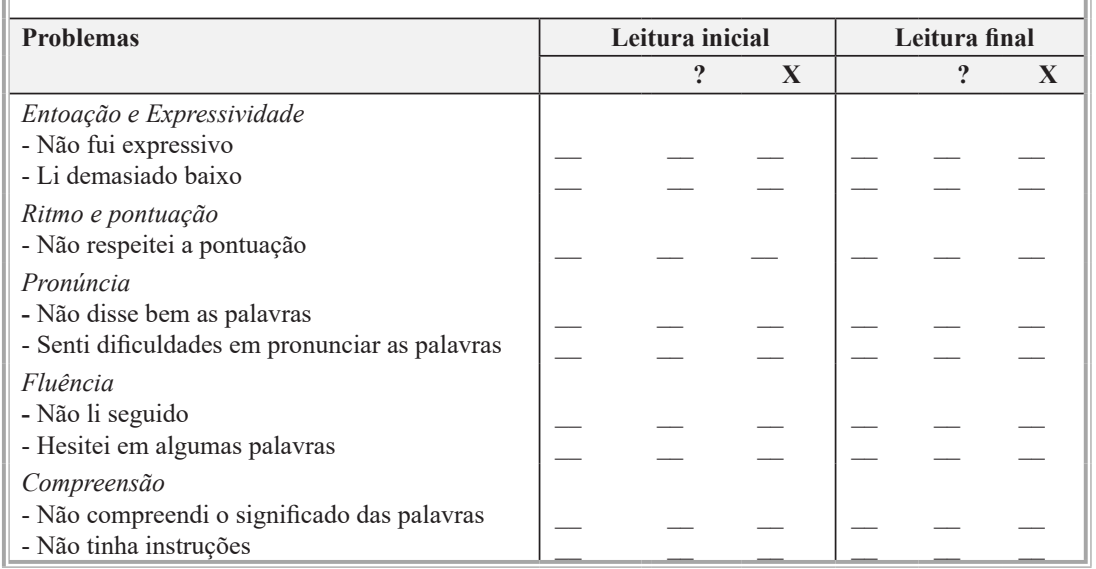

FONTE: Teixeira et al. (2014, p. 137).

Todas as narrativas evidenciam a adoção de uma postura favorável a abordagens de natureza construtivista na construção de uma escola mais democrática (KINCHELOE, 2003, 2006), ilustrando o testemunho seguinte: 
A aprendizagem estratégica e dialógica, oposta a um ensino individualista e competitivo, é essencial ao desenvolvimento de competências de colaboração, corresponsabilização, partilha e negociação, permitindo um maior comprometimento dos alunos nas tarefas propostas, tornando-os construtores do seu saber, respeitando os seus interesses e ritmos de aprendizagem. É necessário realizar com maior frequência este tipo de aulas, acreditando na capacidade dos alunos para criarem condições de resolução dos seus problemas e assumirem um papel ativo na construção das aprendizagens. Esta perspetiva aproxima-nos dos defensores do construtivismo crítico, que "sustentam a noção de que um dos papéis centrais do ensino envolve o comprometimento dos alunos no processo de produção de conhecimento" (KINCHELOE, 2006, p. 11). Por esse motivo, consideramos que uma prática desta natureza dilui as desigualdades e as injustiças existentes na sala de aula, caminhando para uma escola mais democrática e emancipatória. (TEIXEIRA et al. 2014, p. 144).

Reconhece-se, contudo, que uma mudança desta natureza é incerta e inacabada, o que revela a compreensão da natureza complexa, única e indeterminada dos problemas da educação (SCHÖN, 1987), potenciada pelo envolvimento em processos de investigação-ação:

Convictas de que vale sempre a pena investir no desenvolvimento da autonomia dos professores e dos alunos e na experimentação de novas práticas, teremos de continuar a tentar transformar situações problemáticas em desafios, tendo presente o propósito de compreender e melhorar a nossa ação, refletindo criticamente sobre ela no seio da comunidade educativa, numa busca incessante de possíveis respostas ou soluções conducentes à mudança. Assim, findamos este projeto com uma única certeza: "o processo de investigação do professor nunca tem fim nem fica completo” (KINCHELOE, 2003, p. 136). (BRANDÃO; MONTEIRO; COSTA, 2014, p. 67).

Um último aspeto que importa salientar na análise destas narrativas é a construção de "linguagens da experiência" (LARROSA BONDÍA, 2010) que escapam aos cânones de uma escrita despida do "eu" e que não se dissociam dos processos de compreensão e comunicação do vivido. Neste âmbito, as metáforas assumem um papel particularmente significativo na atribuição de sentidos pessoais à experiência, conferindo um cunho criativo aos textos e elevando a sua coerência conceptual. Por exemplo, na narrativa apresentada por Teixeira et al. 
(2014), intitulada "Leitura oral... Qual é o drama afinal?", a metáfora do "drama" refere-se a diversos aspetos: as resistências dos alunos à leitura oral na aula de língua estrangeira, pela exposição pública que implica e inibições que gera; a estratégia didática explorada para a "desdramatização" do problema - preparação da leitura expressiva de um texto dramático; a estruturação da experiência e da narrativa, concebidas como "uma peça em cinco atos"; e, ainda, a descrição de algumas "cenas" do "Ato IV - Abrindo o pano...", no qual as professoras anunciam a sua intenção de recorrer "a um uso criativo (dramático) da linguagem" a fim de evidenciar "as vozes dos principais atores, os alunos". (TEIXEIRA et al., 2014, p. 139). A metáfora do "drama" representa, deste modo, um elemento estruturante da conceptualização da experiência enquanto palco de reconstrução de conceções e práticas de leitura oral. Como sublinha Karlsson (2008), a escrita autobiográfica pode libertar-nos de cânones discursivos escolarizados e conduzir a novas formas de construção e partilha do conhecimento, constituindo uma dimensão importante da emancipação profissional.

\section{Notas finais}

Retomando a metáfora com que iniciei, diria que a estratégia formativa proposta, aqui analisada à luz do seu produto - narrativas da experiência - pode abrir janelas a uma educação mais democrática. Permite traçar percursos de construção de uma visão crítica da educação e de experimentação de práticas alternativas, essenciais à emancipação profissional, nos quais a teoria pública informa, inspira e apoia a interpretação e a reconfiguração da experiência, sem a determinar. Como argumenta Carr (2006, p. 155), embora a teoria educacional não cause a mudança, pode ser apropriada a favor dela. É isso que se observa nas narrativas analisadas, onde a referência a autores é parte integrante de um processo mais vasto de reconstrução de teorias e práticas pessoais, fortemente determinadas pelos contextos da prática e pelas convicções e aspirações das professoras.

Os movimentos de mudança realizados no âmbito desta disciplina são limitados pela curta duração das experiências, pela sua natureza pontual e pela focalização na sala de aula. Como alerta Benson (1996, p. 39), a promoção da autonomia na escola tem sido marcada por processos de despolitização resultantes de uma atenção prioritária a dimensões do aluno em detrimento das condições e forças externas que coartam a autonomia dos professores e face às quais eles se sentem frequentemente impotentes. Ainda assim, as narrativas 
evidenciam a problematização de culturas de ensino dominantes, o que confere à ação das professoras uma direção política assente na luta por "ideias e ideais importantes". (SMYTH, 1997, p. 1102).

O caminho da emancipação rumo a uma educação mais democrática é lento e continuado, baseando-se fundamentalmente na esperança enquanto crença na possibilidade. (VAN MANEN, 1990). Esta ideia é bem ilustrada no testemunho com que termino o texto e que constituia secção final da narrativa de Costa e Barreiro (2014). As professoras colocam-se num plano exterior a si mesmas para contar a sua própria história enquanto "personagens" e "atoras" de um cenário de desenvolvimento profissional, reconhecendo que se trata de uma viagem inacabada de aproximação a um ideal:

\section{Era uma vez... na esperança de...}

Duas personagens reais que partiam numa manhã solarenga de outubro, em busca de novos horizontes para aprender a refletir e a falar sobre a ação pedagógica, impelidas pela insatisfação pessoal e atraídas por um ideal de formação em supervisão. Entre Viana do Castelo e a Universidade do Minho, partilham receios e dilemas, confrontam opiniões, questionam como será o conhecimento desconhecido.

No espaço universidade, um novo espaço de ação, cada texto, cada aula é tempo de reflexão, de (des/re)construção de saberes sobre a ação e para ação.

À medida que foram crescendo na indagação, crescia também a sua perturbação e aprendiam a falar e a investigar sobre a ação. Três meses volvidos, era preciso mostrar como refletir em ação. Por onde começar? O que perguntar? Como perguntar? O que investigar?

Discutiram durante dias. Entre dilemas pessoais, reflexões individuais e confrontos...

Resolveram focalizar a sua atenção noutras histórias de vida, num outro espaço de ação. Viraram, alunos e professoras, atores de uma nova encenação - aprender para falar e falar para aprender -, num processo dialógico de aprender para falar a língua e de falar para aprender a desenvolver competências para a autonomia, numa interdependência reflexiva entre ensinar e aprender.

Com esperança, continuam a viagem de aproximação a um estado ideal de libertação e de emancipação. (COSTA; BARREIRO, 2014, p. 106-107). 


\section{REFERÊNCIAS}

BENSON, Ph. Concepts of autonomy in language learning. In: PEMBERTON, R.; LI, E. S. L.; OR, W. W. F.; PIERSON, H. D. (Org.). Taking control: autonomy in language learning. Hong Kong: Hong Kong University Press, 1996. p. 27-34.

BRANDÃO, A. C.; MONTEIRO, E.; COSTA, L. TPC: da tortura para crianças ao tempo de criar. In: VIEIRA. F. (Org.). Re-conhecendo e transformando a pedagogia: histórias de superVisão. Santo Tirso: De Facto Editores, 2014. p. 51-67.

CARR, W. Education without theory. British Journal of Educational Studies, v. 54, n. 2, p. 136-159, 2006.

CLANDININ, J. (Org.). Handbook of narrative inquiry - mapping a methodology. Thousand Oaks: Sage Publications, 2007.

COSTA, M. C.; BARREIRO, M. P. Aprender para falar... falar para aprender... In: VIEIRA, F. (Org.). Re-conhecendo e transformando a pedagogia: histórias de superVisão. Santo Tirso: De Facto Editores, 2014. p. 89-107.

DEWEY, J. Experience and education. New York: Collier Books, 1963.

FERREIRA, P.; PRECIOSO, A.; VILELA, C.; BARROS, E.; AZEVEDO, I. Quebra de rotinas - ler com olhos de ver? Ver com olhos de ler. In: VIEIRA, F. (Org.). Re-conhecendo e transformando a pedagogia: histórias de superVisão. Santo Tirso: De Facto Editores, 2014. p. 68-88.

FERREIRA, S.; RIBEIRO, L.; PEREIRA, S. Apresentações orais - um caso de (in/ ter)dependências. In: VIEIRA, F. (Org.). Re-conhecendo e transformando a pedagogia: histórias de superVisão. Santo Tirso: De Facto Editores, 2014. p. 108-129.

GIROUX, H. When schools become dead zones of the imagination: a critical pedagogy manifesto. Disponível em: <http://truth-out.org/opinion/item/18133-when-schools-become-dead-zones-of-the-imagination-a-critical-pedagogy-manifesto $>$. Acesso em: 15 ago. 2013.

JIMÉNEZ RAYA, M.; LAMB, T.; VIEIRA, F. Pedagogy for autonomy in language education in Europe. Dublin: Authentik, 2007.

JIMÉNEZ RAYA, M.; VIEIRA, F. Enhancing autonomy in language education: A case-based approach to teacher and learner development. Berlin/New York: Mouton de Gruyter, 2015.

JOHNSON, K.; GOLOMBEK, P. (Org.). Teachers' narrative inquiry as professional development. Cambridge: CUP, 2002.

KARLSON, L. Turning the kaleidoscope - (E)fl educational experience and inquiry as auto/biography. Helsinki: University of Helsinki Language Centre, 2008. 
KINCHELOE, J. Teachers as researchers: qualitative inquiry as a path to empowerment. London \& New York: Routledge Falmer, 2003.

KINCHELOE, J. Construtivismo crítico. Mangualde: Edições Pedago, 2006.

LARROSA BONDÍA, J. Herido de realidad y en busca de realidad. Notas sobre los lenguajes de la experiencia. In: CONTRERAS, J.; PÉREZ DE LARA, N. (Org.). Investigar la experiencia educativa. Madrid: Edições Morata, 2010. p. 87-116.

MOREIRA, M. A. Materiais de apoio à regulação do trabalho de projeto: papel dos alunos e do professsor(-tutor). In: VIEIRA, F.; MOREIRA, M. A. (Org.). Cadernos 3 do GT-PA. Braga: Universidade do Minho, 2003. p. 35-38.

MOREIRA, M. A. Quebrando os silêncios das histórias únicas: as narrativas profissionais como contranarrativas na investigação e formação em supervisão. Revista Brasileira de Pesquisa sobre Formação Docente, v. 3, n. 5, p. 11-19, 2011 a.

MOREIRA, M.A. (Org.). Narrativas dialogadas na investigação, formação e supervisão de professores. Mangualde: Edições Pedago, $2011 \mathrm{~b}$.

SCHÖN, D. Educating the reflective practitioner. San Francisco: Jossey-Bass Publishers, 1987.

SHOR, I. Empowering education: critical teaching for social change. Chicago: University of Chicago, 1992.

SHULMAN, J. (Org.). Case methods in teacher education. New York: Teachers College Press, 1992.

SHULMAN, L. Just in case - reflections on learning from experience. In: WILSON, $\mathrm{S}$. (Org.). The wisdom of practice - essays on teaching, learning, and learning to teach. San Francisco: Jossey Bass, 2004. p. 463-482.

SMYTH, J. Teaching and social policy: images of teaching for democratic change. In: BIDDLE, B. J.; GOOD, T. L.; GOODSON, I. F. (Org.). International handbook of teachers and teaching. Dordrecht: Kluwer Academic Publishers, 1997. p. 1081-1114.

TEIXEIRA, A. C.; NEVES, A. I.; SERDOURA, H.; MONTEIRO, I. Leitura oral... Qual é o drama afinal?. In: VIEIRA. F. (Org.). Re-conhecendo e transformando a pedagogia: histórias de superVisão. Santo Tirso: De Facto Editores, 2014. p. 130-144.

VAN MANEN, M. Researching lived experience - human science for an action sensitive pedagogy. New York: The State University of New York, 1990.

VASCONCELOS, A.; COSTA, I.; GONÇALVES, P. Todos a bordo - uma experiência de trabalho colaborativo. In: VIEIRA, F. (Org.). Re-conhecendo e transformando a pedagogia: histórias de superVisão. Santo Tirso: De Facto Editores, 2014. p. 145-168.

VIEIRA, F. Para uma pedagogia da experiência na formação pós-graduada de professores. Indagatio Didactica, v. 1. n. 1, p. 32-75, 2009. 
VIEIRA, F. Supervisão: (re)produzir a pedagogia. In: RANGEL, M.; FREIRE, W. (Org.). Supervisão escolar: avanços de conceitos. Rio de Janeiro: Wak Editora, 2011a. p. 89-121.

VIEIRA, F. A experiência educativa como espaço de (trans)formação profissional. Linguarum Arena, v. 2, p. 9-25, 2011 b.

VIEIRA, F. O lugar da experiência na formação de professores. In: SOARES, S. R.; BORBA, V. C. M. (Org.). Ensino e aprendizagens: análise de práticas. Salvador: EDUNEB, 2012. (Série Práxis e Docência Universitária, v. 1). p. 25-75.

VIEIRA, F. (Org.). Re-conhecendo e transformando a pedagogia: histórias de superVisão. Santo Tirso: De Facto Editores, 2014a.

VIEIRA, F. (Org.). Quando os professores investigam a pedagogia, em busca de uma educação mais democrática. Mangualde: Pedago, 2014b.

WEBSTER, L.; MERTOVA, P. Using narrative inquiry as a research method - an introduction to using critical event narrative analysis in research on teaching and learning. London \& New York: Routledge, 2007.

Texto recebido em 03 de outubro de 2016. Texto aprovado em 04 de novembro de 2016. 
